\title{
Multi-Media Campaigns, Interpersonal Contacts and Contraceptive Behaviour in Southwest Nigeria
}

\author{
Akinrinola Bankole \& Alfred A. Adewuyi
}

\begin{abstract}
Recent evidence suggests that mass media may be an effective tool for motivating people to adopt family planning. Little is known, however, about the process by which this takes place. In this exploratory study, we argue that following an exposure to mass media message(s) about family planning, interpersonal discussion of such message(s) is an important intermediate stage in the process of deciding to use or not to use contraception. If this is the case, interpersonal discussion is expected to enhance or attenuate the effects of exposure to media messages on contraceptive behaviour. Our results show that there is a significant positive relationship between exposure to media messages and contraceptive use in Southwest Nigeria. Furthermore, among women who are exposed to media messages, those who discuss the messages with other people are more likely to use contraception compared with those who did not discuss the messages.
\end{abstract}

\section{Résumé}

Les résultats des dernières recherches suggèrent que les moyens de communication de masse peuvent s'avérer être un outil efficace de motivation des populations à adopter la planification familiale. Toutefois, il existe très peu de données sur le processus par lequel s'opère une telle activité. Dans cette étude exploratoire, notre propos consiste à soutenir que, par suite d'une forte exposition à des messages portant sur la planification familiale par le truchement des moyens de communication de masse, la discussion interpersonnelle de ces messages-là constitue une étape intermédiaire importante dans le processus de prise de décision quant à l'utilisation ou non de la contraception. Si cela est vrai, la discussion interpersonnelle devra soit renforcer, soit atténuer les effets de l'exposition aux messages passés par les médias sur le comportement par rapport à la contraception. Les résultats de nos recherches montrent qu'il existe une relation positive de fond entre l'exposition aux messages véhiculés par les médias et l'utilisation des moyens contraceptifs au Sud-ouest du Nigéria. En outre, au nombre des femmes exposées aux messages véhiculés par les médias, celles qui en discutent avec d'autres sont plus enclines à utiliser les méthodes contraceptives par opposition à celles qui n'ont pas discuté des messages en question.

\section{Introduction}

In contrast to widespread thinking in the 1970s, the efficacy of mass media for promoting family planning is increasingly widely accepted today. Recent findings suggest that exposure to family planning messages on radio, television and the print media is strongly associated with contraceptive behaviour (Piotrow et al, 1990; Kincaid et al, 1992; Westoff and Rodríguez, 1993), although certain issues (such as the problem of disentangling the direction of causality between the two events) are yet to be conclusively resolved. One important element of this relationship that requires attention, however, is the process by which mass media messages lead to a decision to use or not to use (or to continue or not to continue) contraception. Little is currently known about what takes place between the time a woman or man is exposed to media message(s) and the time she or he makes a decision about family planning.

Information seeking is believed to be the first important step an individual takes in the process of decision-making following an exposure to family planning messages in the mass media (Piotrow et al, 1994). She/he may want more information on the appropriate method to use, how to obtain it, the risks involved or the cost of obtaining the method. In anticipation of this step of information seeking, effective mass media campaigns about family planning point the audience to how and where further information could be obtained. In addition to seeking information the individual may also want to seek the consent, opinion or advice of her or his spouse, relative or friend before taking any action. On the other hand, people who have been exposed to family planning messages may discuss them with others just for their information. As the discussion takes place, however, the contents as well as the objectives of the messages may be critically evaluated. 
Beyond examining the direct effects of exposure to mass media messages on contraceptive behaviour, it is important to ask questions such as: How prevalent is post-exposure interpersonal discussion of media messages? Does interpersonal discussion of media messages have additional effects on contraceptive behaviour? What is the outcome of the additional effects? These questions are important for at least two reasons. First, a prevailing argument against the use of mass media is that changes in behaviour more often follow interpersonal contacts than mass media messages (see Bogue, 1962; Hyman and Sheatsley, 1974). But mass media messages and interpersonal contacts have a synergistic effect. Second, unlike the effect of mass media messages, which is not expected to be negative, interpersonal contact may produce a negative impact (Bhatia et al., 1981). For instance, whether or not a woman who develops an interest in adopting contraception will carry through the desire may depend on the orientation of the individuals contacted and the extent to which she values their opinions (Piotrow et al., 1994).

In this article, we examine the relationship between exposure to three mass media campaigns undertaken in Nigeria between 1989 and 1992 and the contraceptive behaviour of women in the southwestern region of the country. We also investigate the additional association between interpersonal discussion of the campaigns and the contraceptive behaviour of those who were exposed to the campaigns.

\section{Mass Media Campaign and Post-Exposure Discussion}

How prevalent is interpersonal discussion of mass media messages about family planning? Research findings suggest that a substantial proportion of women who are exposed to mass media messages share them with other people, for a variety of reasons. One of the main objectives of a multi-media campaign on sexual responsibility and family planning in Latin America was to induce teenagers to think about sexual responsibility and to start talking to others about it. An evaluation study of the campaign's effects (Kincaid et al, 1988) showed that half of the respondents talked to their female friends about the songs in the campaign and 32 per cent talked to their male friends. About 50 per cent talked to either of the parents while only 7 per cent talked to their teachers about the songs. Another report of a similar campaign in the Philippines indicated that 92 per cent of a sample of youths interviewed after the campaign recalled the song "I Still Believe." Forty-four percent of those who recalled the song said that they discussed it with friends or parents (Rimon et al., 1994).

In Zimbabwe, a multi-media campaign consisting of a radio drama series, motivational talks and pamphlets with family planning themes was intended to promote family planning among men. A report of the campaign noted that 60 per cent of those who were exposed to the radio soap opera talked to others about it. The respondents identified their audience as consisting of mostly their male friends, followed by male relatives and spouses (Piotrow, et al., 1994). Also in Nigeria, a mass media campaign involving two songs and music videos was undertaken in 1989 to promote family planning and certain sources of obtaining family planning services. An evaluation of the impact of the campaign after the broadcast among men aged 15-35 in three cities indicated that 64 per cent of the respondents recalled the songs and 34 per cent talked to someone about the songs.

Does interpersonal discussion influence behaviour? Interpersonal contacts have long been identified as a potent means of changing behaviour (Katz and Lazarsfeld, 1955). It is believed that people are more likely to change their behaviour when they are encouraged to do so by other individuals they know, like or respect. Thus, when individuals talk about mass media campaigns about family planning with others, the response they receive may be important for the decision they eventually make. This becomes very important given that the majority of the people who constitute the audience in such discussions tend to be spouses, relatives and friends. The literature suggests that interpersonal contacts can reinforce or attenuate the positive effects of mass media messages.

Evidence from a focus group study among a group of women (Bankole, 1994) showed that discussing with the husband following an exposure to a mass media campaign about family planning can constitute either a bottleneck or an encouragement to adopting family planning. The participants were asked to recall the campaigns that they had watched or listened to, and to describe any action they took as a result of being exposed to the campaigns. The following quotes illustrate the point that messages can have both positive and negative effects on individual recipients. 
"I actually watched the family planning show with my husband and we discussed the message. He insisted that he would never support my obtaining a family planning method because once a woman does it she becomes promiscuous and uncontrollable." (p.20)

"When I heard the family planning message, I told my husband about it. He told me to go to the hospital to inquire more about family planning. When I went, they gaveme some information and recommended the pill that I am currently using." (p.20)

The uncertainty about the direction of the effects of interpersonal communication on contraceptive behaviour becomes more evident from the reports of a study of peer pressure and contraceptive sterilization in Bangladesh. The study was based on interviews with 275 women who were sterilized in 1978 and another 175 women who expressed interest in the procedure and registered for it but failed to return to the clinic for the surgery (Bhatia et al., 1981). Of the sterilized women who were interviewed, 81 per cent were reported to have consulted with their female relatives about the procedure to seek their support and assurance. They received overwhelming support from both the relatives (87 per cent) and their husbands and mother-in-law (95 per cent). Another study in El Salvador among women who were sterilized noted similarly that the majority of the women received positive reaction from those who had earlier been sterilized and from their husbands (Bertrand et al., 1986). That these women in both studies went ahead to obtain the procedure cannot be dissociated from the social approval they received.

The Bangladesh study reported, on the other hand, that of the women who failed to return to the clinic for the procedure, 52 per cent said that they decided against sterilization because their husbands opposed it. Another 13 per cent cited objections from spouses, friends and relatives as the reason for their action. Again, why these women changed their mind may not be independent of the negative reactions they received from their relatives and friends. Rumour and misinformation have been found to have negative impact on pill usage in Egypt, and the most frequently reported sources of the rumour that pill causes weakness are friends or neighbours followed by spouses and relatives (DeClerque et al., 1986).

\section{The Data}

The data used for our study were obtained through a survey conducted in 1993 as a follow-up to the Nigeria Demographic and Health Survey (NDHS). The survey was undertaken in three states - Lagos, Oyo, and Osun - with the objective of re-interviewing the sub-sample of the women interviewed in the NDHS in those states. Out of the 1221 married women aged 15-44 originally interviewed in that survey in 1990, 770 women who were presumed to be part of the original sample were successfully interviewed (Westoff et al., 1994). We analyzed only the information collected in the 1993 interviews in this article. The data consist of information on the characteristics and the reproductive histories of the respondents as well as information on their exposure to family planning campaigns in the mass media. The respondents were asked to recall whether or not they have seen or listened to certain campaigns undertaken in the country since 1989. Those who said that they have been exposed to at least one of them were asked to recall whether or not they ever watched and/or discussed any of them with other people.

The campaigns - "The Songs and Music Videos" (songs/music video), "Eni A Wi Fun" (To Be Forewarned) and the "Public Service Announcements/National Family Planning Logo" (PSA/logo) have been described in detail elsewhere by the Population Communication Services of the Johns Hopkins University; only a brief description of each of them is provided here.

The campaigns utilized the "enter-educate" approach to promote the ideal of a small family size and to motivate the Nigerian people to adopt family planning. The first consisted of two popular songs and music videos ("Choices" and "Wait For Me") featuring two popular musicians - King Sunny Ade and Onyeka Onwenu. The main objective of the project was to promote family planning, the Planned Parenthood Federation of Nigeria clinics and government services. The campaign was launched in August 1989 with the release of the two songs with the theme of sexual responsibility. Extensive publicity and public relations activities were undertaken by the musicians throughout the country and the songs were simultaneously broadcast on the radio and television (Kincaid et al., 1992). At least 
75,000 albums and cassettes of the songs were reportedly sold following the launching. The project was said to also have received massive free press coverage both in the electronic and print media (JHU/PCS, 1990).

The second campaign consisted of a Yoruba drama video featuring a popular Yoruba comedian (Moses Olaiya - "Baba Sala") and his group. The objective of the drama video programme called "Eni A Wi Fun" (To Be Forewarned - TBF for short) was to promote primary health care and family planning in the Yoruba-speaking states of southwest Nigeria, particularly among the rural dwellers (JHU/PCS, 1990). The campaign was launched in December 1990 with the premiere screening of the drama video at the Ibadan Cultural Centre, capital of Oyo State. About 2000 people were said to have attended the show. Since that time, the drama was presented several times on the television and mobile cinema vans (for the rural audience). The campaign also featured health workers who usually attended the showing of the video to provide additional information, answer questions, provide clarifications and direct people to local health and family planning centres (JHU/PCS, 1993).

The last of the campaigns involved a nationwide broadcast of 14 Public Service Announcements (PSAs) on the radio and television for a period of six months (June - November, 1992). The PSAs were developed around five separate episodes or events, each of which was intended to promote the small family size ideal and family planning. The announcements were broadcast in English, Pidgin, Hausa, Igbo and Yoruba languages, and each of them concluded with the promotion of the National Family Planning Logo (Kiragu et al., 1993). The logo which shows a couple holding a baby against a map of Nigeria was formally launched in September 1991. Its objective is "to increase awareness and demand for family planning as well as identify outlets where family planning information and services are available" (JHU/PCS, 1991). About one million pieces of materials such as posters billboards, danglers, car stickers, indoor stickers and badges featuring the logo were produced and distributed (Kiragu et al., 1993).

\section{Determinants of Exposure to Media Campaigns and Interpersonal Contacts}

Figure 1 shows the percentages of the respondents who were exposed to the three media campaigns considered in this study. The most recalled of the campaigns was the PSA/logo. About 76 per cent claimed to have seen or listened to the campaign. This figure compares quite closely with the 74 per cent exposure reported from a sample survey conducted at the end of 1992 (Kiragu, et al., 1993). About 51 per cent of our respondents watched or listened to the songs/music videos campaign. An earlier study reported that 64 per cent of a sample of urban residents reported being exposed to the campaign about five months after the launching (JHU/PCS, 1990). The Yoruba drama video ("Eni A Wi Fun") was watched by only 36.8 per cent of the respondents.

Some of the differences between the exposure figures for the campaigns can be explained by the recency and pervasiveness of the campaigns. More recently aired and/or more frequently aired campaigns were more likely to be remembered and reported than those that were broadcast earlier or less frequently. The PSA/logo was the most recently and perhaps the most frequently aired of the campaigns. On the other hand, the Yoruba drama video was the least aired and the most limited in terms of its coverage.

An examination of the results suggests a strong cumulative association between exposure to the three campaigns. Almost every respondent who reported being exposed to "Eni A Wi Fun" was also exposed to the "songs/music video" and the PSA/logo. Similarly, most of those who were not exposed to "Eni A Wi Fun" but had seen or heard the songs/music videos had also seen or heard the PSA/logo campaign. Therefore, we created a cumulative scale of exposure to multi-media campaigns using the Gutman's cumulative scale approach (see Gutman, 1950; Westoff and Rodríguez, 1993). Table 1 shows the distribution of the cumulative scale. It indicates the order of the pervasiveness of the campaigns in terms of the number of the campaigns to which each respondent was exposed.

About 18 per cent of the respondents didn't recall having seen or listened to any of the three campaigns. Twenty-five percent had seen or listened to the PSA/logo while 31 per cent had been exposed to both the PSA/logo and the songs/music videos. Only 25.5 per cent recalled to have seen or listened to the three campaigns. About 42 per cent of those who were exposed to the campaigns 
recalled having talked about at least one of them with other people, particularly spouses, friends, relatives and health workers.

To better understand the dynamics of the exposure to and discussion of these campaigns, we examined the extent to which the exposure and the discussion of the campaigns varied by socioeconomic and demographic and demographic characteristics of the respondents. First, we used the ordered logit regression model to examine the correlates of exposure to the campaigns. Then, among those who were exposed to at least one campaign, we used the logit regression model to identify the background variables that are related to interpersonal discussion of the campaigns.

Figure 2 presents the effects of the socio-economic and demographic variables on exposure to media campaign about family planning. The number of living children, education, the frequency of listening to the radio and the frequency of watching television were significant predictors of exposure to the media campaigns. The odds of being exposed to the campaigns increases with the number of living children up to the sixth child and then declined as the number of living children increased. While this pattern of effects is similar to earlier findings in Kenya (Westoff and Rodríguez, 1993) and Nigeria (Westoff et al., 1994) the negative portion of the relationship remains puzzling. One would expect the number of living children to be consistently positively related to exposure to media campaigns. It may be the case that women with very large families are less attracted or sympathetic to the ideas in such messages, or have less time or opportunity to watch television or listen to radio.

Education exerted a very strong positive impact on exposure to media campaigns. For instance, the odds of being exposed to the PSA/logo campaign (or any of the other campaigns) for a woman with a secondary or higher education were 3.5 times as high as for a woman with no education. As one would expect, women who listened to the radio or watched television every day were more likely to have seen or heard one of the media campaigns about family planning. These effects are strongest for television viewers.

Figure 3 shows the effects of the background variables on odds of discussing at least one of the media campaigns with other people, for those who were exposed to the campaigns. The most important determinant of interpersonal discussion of the campaigns was education. Compared to no education, having a primary education was associated with an 85 per cent increase in the odds of discussing a campaign while a secondary or more education increased the odds of discussing a campaign by 136 per cent. Net of the effects of the other variables, the age of the woman also determined whether or not she talked about a campaign.

Younger women were more likely to discuss a campaign that they had heard or seen than were older woman. Women in polygynous marriages also tended to be more disposed to discussing media campaigns about family planning. Because a polygynously married woman and her children compete with the other wives and their children for the attention and the resources of the husband, she may be more interested in family planning programmes than a counterpart in a monogamous union. The presence of another wife could also provide opportunities for a polygynously married woman to discuss information about family planning with her co-wife.

The frequency of listening to the radio also exerted a significant impact on the odds of discussing the media campaigns with others. Women who listened to the radio every day were two times as likely to discuss a campaign with other people as those who listened to the radio less than once a week. Television viewing also shows a similar pattern of effects, but the relationship is not significant. It may be that when a woman hears a media campaign about family planning frequently on the radio, the absence of the visual component of the campaign tends to increase her desire to discuss the programme with other people in order to seek clarification or more information about family planning. The number of living children showed a positive association with the odds of discussing a campaign, but the effects were not statistically significant.

\section{Media Campaigns and Interpersonal Contacts on Contraceptive Behaviour}

The analysis of the relationships between exposure to and discussion of media campaigns and the contraceptive behaviour of the respondents was done in two stages. First, we used logit regression 
models to examine the effects of exposure to the campaigns on contraceptive use and intention to use in the future. The major explanatory variable of interest here is the cumulative scale of campaign exposure, represented in the models by three dummy variables. Second, for women who were exposed to at least one campaign, we examined the impact of interpersonal discussion of the campaign(s) on contraceptive use and intention. Interpersonal discussion is defined as a dummy variable where a respondent is given a value of 1 if she discussed a campaign with other people, and $\mathrm{O}$ otherwise. The results of the regression models are been summarized in Tables 2 and 3.

The results of the relationship between exposure to media campaigns and current use of modern contraceptives is presented in Panel 1 of Table 2 and Figure 4. The results indicate that being exposed to the campaigns was significantly associated with current contraceptive behaviour net of the effects of other variables. The proportion currently using a modern method among the women who were exposed to the PSA/logo alone was 11.5 per cent higher than that of the women who were not exposed to any of the campaigns. This difference increased to 28 per cent for those who were exposed to the three campaigns. The effects of discussing a campaign with others on current use of contraceptives are shown in Panel 1 of Table 3 and Figure 4. After controlling for other variables, close to 30 per cent of the women who were exposed to a campaign and talked about it with other people were current users of modern methods compared to 21 per cent of those who were exposed but did not discuss a campaign with others.

In Table 2 (Panel 2) and Figure 5, we present the effects of exposure to the media campaigns on intention to use a method in the future. Women who were exposed to a media campaign about family planning were more likely to intend to use a method sometime in the future than those who were not exposed. Net of the effects of other variables, 32 per cent of the women who were exposed to the PSA/logo intended to use a method compared to about 24 per cent of those who were not exposed to the campaigns. Being exposed to the three campaigns only modestly increases the proportion of exposed women who intended to use a method to 34 per cent. This suggests that exposure to the PSA/logo alone produced most of the observed positive attitude towards future use of contraception.

Respondents who could not make up their minds to use or not to use a method in the future were not systematically different by exposure to the media campaigns. Only those who were exposed to both the PSA/logo and songs/music videos were more undecided than those who were not exposed to any of the campaigns. It is not clear what components of the two campaigns made their audiences tend to be more undecided than to be decided not to use a method in the future. Perhaps the joint influence of the two campaigns on a woman who otherwise would not have been interested in contraception was to prompt her to be more open and to desire more information or clarifications before making up her mind to use or not to use.

Table 3 (Panel 2) and Figure 5 present the results of the relationship between discussing a campaign and intention to use a method in the future. Women who were exposed to a campaign and discussed it with other people were more likely to intend to use a method sometime in the future. After controlling for the effects of other variables, 43.8 per cent of the women who were exposed to and discussed a campaign with others intended to use a method compared to only 26.3 per cent of those who were exposed but discussed no campaign with anyone. In effect, interpersonal discussion tended to help a woman decide to use a method in the future rather than to decide against future use. On the other hand, being undecided about future use of contraception was not significantly associated with interpersonal discussion of the campaigns. The slightly lower proportion undecided among the women who discussed a campaign with others suggests, if anything, that discussing a campaign may help a woman to decide against using contraception in the future instead of being undecided.

\section{Conclusion}

Evidence from this study suggests that quite a substantial proportion of the people in the southwestern Nigeria are exposed to mass media campaigns about family planning. Exposure to media campaigns tends to be associated with the number of living children, education and the frequency of listening to the radio or watching television. Furthermore, people do not just keep the information they received from the campaigns to themselves. Rather, there is some sharing of such information among them. Age, education, type of marriage and the frequency of listening to the radio are important determinants of the odds of discussing media campaigns with other people. 
The main question asked in this study is whether the sharing of information from mass media campaigns about family planning tends to enhances or attenuates the association between exposure to media messages and contraceptive behaviour. Because of the cross-sectional nature of our data, our results cannot be strictly interpreted to imply causality. What we have established are the direction and magnitude of association between the variables. Our findings indicate that exposure to media campaigns about family planning has a strong positive association with contraceptive behaviour. It is conceivable that being exposed to media messages about family planning helps to initiate contraceptive adoption as well as to assure contraceptive continuation. The results also show that being exposed to more than one campaign may have cumulative effects on contraceptive behaviour. In addition to the positive association between exposure to the campaigns, talking about the campaigns to other people may help to promote the objectives of the media messages. It seems that women who discuss the campaigns with other people tend to receive additional motivation to practise or to intend to practise family planning.

While it is reassuring that interpersonal discussion tends to reinforce rather than attenuate the association between exposure to media messages and contraceptive behaviour, further research is necessary to better understand the process by which this occurs. For instance, we said earlier that the effects of interpersonal discussion may depend on who a woman discussed the campaign(s) with. It is also conceivable that a woman will be selective of who she discusses family planning information with. If she becomes disposed to using contraception after being exposed to a family planning message, she is more likely to discuss with someone who she believes will be supportive of the idea, such as a friend rather than a spouse or relative. We were unable to examine these issues in the present paper because we have no information on who our respondents said that they discussed the messages with. Meanwhile, it is desirable that a mass media campaign should include well planned interpersonal contacts in order to ensure that the audience of the campaign who may need further clarifications or have some questions to be answered seek such information from people who will give them the correct responses. In the absence of this, many individuals will be forced to base their decisions on whatever information they can get, even if it is from uninformed sources.

Table 1:Cummulative Scale of Exposure to Multi-Media Campaigns

\begin{tabular}{|c|c|c|c|}
\hline Score & Media Campaign* & Number & Percent \\
\hline 0 & No campaign reported & 142 & 18.4 \\
\hline 1 & PSA/logo only & 193 & 25.1 \\
\hline 2 & PSA/logo and Songs/Music Videos & 239 & 31.0 \\
\hline 3 & All three campaigns including TBF & 196 & 25.5 \\
\hline Total & & 770 & 100.0 \\
\hline
\end{tabular}

*TBF refers to "Eni A Wi Fun" (To Be Forewarned). 
Table 2:Effects of Exposure to Multi-media Campaigns on Contraceptive Behavior

\begin{tabular}{|c|c|c|c|c|c|c|c|c|}
\hline \multirow{2}{*}{$\begin{array}{l}\text { Reproductive } \\
\text { Behavior/Intention }\end{array}$} & & \multicolumn{7}{|c|}{ Exposure to Multi-media Campaigns } \\
\hline & & None & $\begin{array}{l}\text { PSA/ } \\
\text { Logo }\end{array}$ & $\begin{array}{c}\text { +Songs/ } \\
\text { M.V }\end{array}$ & $+\mathrm{TBF}$ & All & $\begin{array}{l}\text { Chi- } \\
\text { sp } \\
\text { or F }\end{array}$ & df \\
\hline $\begin{array}{l}\text { Ever-use of } \\
\text { Contraception }\end{array}$ & $\mathbf{N}$ & 142 & 193 & 239 & 196 & 770 & & \\
\hline \multirow{2}{*}{$\%$ used modern method } & & 12.2 & 31.0 & 41.9 & 54.4 & 34.4 & 91.6 & 3 \\
\hline & Adj & 16.9 & 32.1 & 38.0 & 52.6 & 34.4 & 42.2 & 3 \\
\hline \multirow{3}{*}{$\begin{array}{l}\text { Current Use of } \\
\text { Contraception } \\
\% \text { using of modern } \\
\text { method }\end{array}$} & $\mathbf{N}$ & 133 & 181 & 222 & 198 & 720 & & \\
\hline & & 5.5 & 18.9 & 23.3 & 37.4 & 20.8 & 63.0 & 3 \\
\hline & Adj & 8.2 & 19.7 & 21.0 & 36.6 & 20.8 & 32.2 & 3 \\
\hline \multirow[t]{5}{*}{$\begin{array}{l}\text { Intention to Use } \\
\text { Contraception }\end{array}$} & $\mathbf{N}$ & 134 & 156 & 173 & 112 & 575 & & \\
\hline & & 23.8 & 32.3 & 34.2 & 36.0 & 30.6 & 15.5 & 6 \\
\hline & Adj. & 25.2 & 32.4 & 33.2 & 34.5 & 30.6 & 9.9 & 6 \\
\hline & Unadj. & 18.7 & 20.5 & 27.7 & 20.0 & 21.7 & 15.5 & 6 \\
\hline & Adj. & 18.4 & 20.2 & 28.2 & 19.9 & 21.7 & 9.9 & 6 \\
\hline $\begin{array}{l}\% \text { not } \\
\text { sure of } \\
\text { intention }\end{array}$ & & & & & & & & \\
\hline
\end{tabular}

The adjusted percentages for current use of contraception are derived from the results of a logit regression model, while the ones for intention to use contraception in the future are based on the results of a multinomial logit regression model. In both cases we controlled for variables that may influence the relationship. The figures have been scaled to reproduce exactly the sample total. 
Table 3:Effects of Interpersonal Discussion of Multi-Media Campaign on Contraceptive Behavior

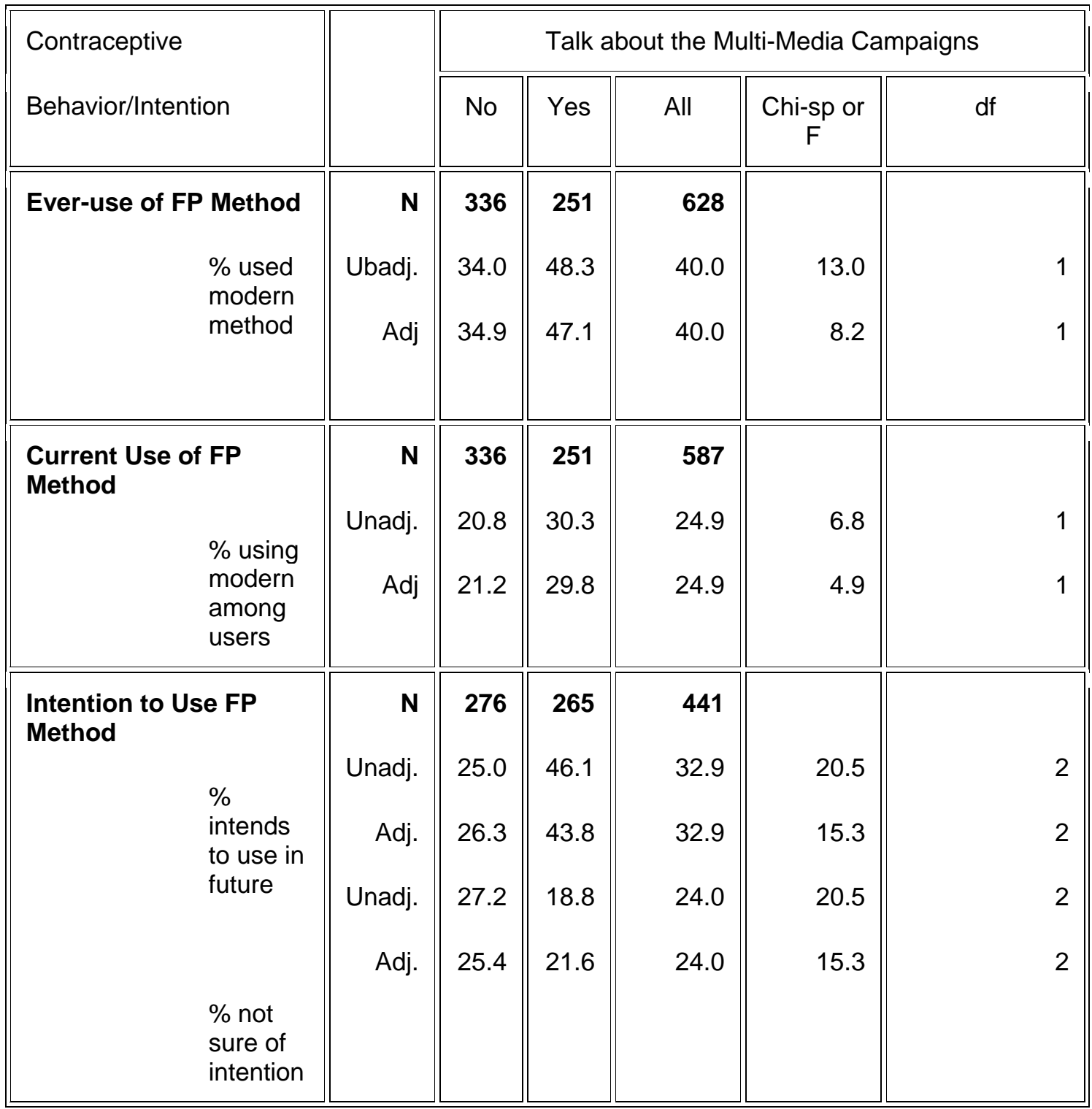

The adjusted percentages for current use of contraception are derived from the results of a logit regression model, while the ones for intention to use contraception in the future are based on the results of a multinomial logit regression model. In both cases, we controlled for variables that may influence the relationship. The figures have been scaled to reproduced exactly the sample total.

\section{References}

- Bankole, A. (1994). The Role of Mass Media in Family Planning Promotion in Nigeria. DHS Working Papers, Number 11. Macro International Inc. Calverton, Maryland, USA.

- $\quad$ Bertrand, J.T., E.G. Landry and J.D.A. Zelaya. (1986). "Is female sterilization voluntary in El Salvador?" International Family Planning Perspectives, 12: 40-48.

- Bhatia, S., A.S.G. Faruque and J. Chakraborth. (1981). "Peer pressures and the use of contraceptive sterilization in Rural Bangladesh." International Family Planning Perspectives, 6: 107-113.

- Bogue, D.J. (1962). Some tentative recommendations for a 'sociological correct' family planning communications and motivation programme in India, pp. 503-538, in C. V. Kiser (ed) Research in Family Planning. Princeton: Princeton University Press. 
- DeClerque, J., A.O. Tsui, M.F. Abul-Ata and D. Barcelona. (1986). "Rumour, misinformation and oral contraceptive use in Egypt." Social Science and Medicine, 23: 83-92.

- Gutman, L. (1950). The basis for scalogram analysis, pp. 60-90, in S. A. Stouffer et al. Measurement and Prediction. Princeton: Princeton University Press.

- Hyman, H.H. and P.B. Sheatsley. (1974). "Some reasons why information campaigns fail." Public Opinion Quarterly, 2: 412-423.

- Katz, E., and P.F. Lazarsfeld. (1955). Personal Influence: The Part Played by People in the Flow of Mass Communications. New York: The Free Press of Glencoe.

- Kincaid, D.L., J.R.J. Elias, P. Coleman, F. Segura. (1988). Getting the Message: The Communication for Young People Project. A.I.D. Evaluation Special Study No. 56.

- Kincaid, D.L., J.G. Rimon, P.T. Piotrow and P.L. Coleman. (1992). The Enter-educate: Using Entertainment to Change Health Behaviour. Paper presented at the annual meeting of the Population Association of America, Denver, April 30 to May 2, 1992.

- Kiragu, K., D.L. Kincaid, C. Church, J.G. Rimon, H. Zhang, S.C Krenn, J.K.T. Ajiboye, I. George, B. Kusimeju, O.Kalu, A. Adewuyi, A.K. Omideyi and M.O. Raimi. (1993). Impact of Complementary Multi-Media Campaigns on Family Planning Behaviour in Nigeria. Paper Presented at the 121st Annual APHA Meeting, San Francisco, October 25, 1993.

- Piotrow, P.T., G.J Rimon II, K. Winnard, D.L. Kincaid, D. Huntington and J. Conviser. (1990). "Mass media family planning promotion in Nigerian cities." Studies in Family Planning, 21(5): 265-274.

- Piotrow, P.T., K.A. Treiman, J.G. Rimon II, S.H Yun, and B.V. Lozare. (1994). Strategies for Family Planning Promotion. World Bank Technical Paper, ISSN 0253-7494, Number 223.

- Rimon II, J.G., K.A Treiman, D.L. Kincaid, A.Silayan-Go, M.S Camacho-Reyes, R. M. Abejuela, and P.L. Coleman. (1994). Promoting Sexual Responsibility in the Philippines Through Music: An Enter-Educate Approach. Occasional Paper Series, Number 3. Centre for Communication Programs, Johns Hopkins University, Baltimore, Maryland, U.S.A.

- The Johns Hopkins University, Population Communication Services (JHU/PCS). (1990). Nigeria Family Health Services Project Information Education and Communication (IEC) Component. Year Two Activities April 1989 to March 1990.

- The Johns Hopkins University, Population Communication Services (JHU/PCS). (1990). Nigeria Family Health Services Project Information Education and Communication (IEC) Component. Year Three Activities April 1990 to March 1991.

- The Johns Hopkins University, Population Communication Services (JHU/PCS). (1993). "Eni A Wi Fun" (To Be Forewarned). Nigeria Family Health Services Project, Information Education and Communication (IEC) Component.

- Westoff, C.F. and G. Rodríguez (1993). The Mass Media and Family Planning in Kenya. DHS Working Papers, Number 4. Macro International Inc., Columbia, Maryland, U.S.A.

- Westoff, C.F., G. Rodríguez and A. Bankole. (1994). Family Planning and Mass Media Messages. The EVALUATION Project Working Papers, Document \#IM0802, Carolina Population Centre, University of North Carolina at Chapel Hill, Chapel Hill, North Carolina, USA 